IAUSymposium IAU Symposium

19- 23 January 2009,

Paris, France

The Role of

Astronomy in

Society and

Culture

Valls-Gabaud

Boksenberg

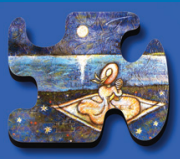

Proceedings of the

International
Astronomical Union

TIT

$\Psi / \Delta]$

CAMbridge

$19-23$ January 2009,

Paris, France
ISSN 1743-9213

International Astronomical Union

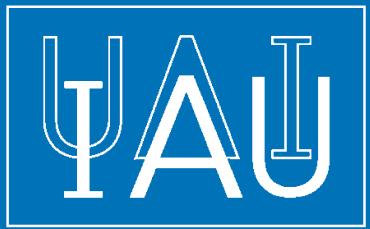

CAMBRIDGE UNIVERSITY PRESS

Proceedings of the International Astronomical Union

\title{
The Role of
}

\section{Astronomy in Society and Culture}

Edited by

\section{David Valls-Gabaud}

Alexander Boksenberg

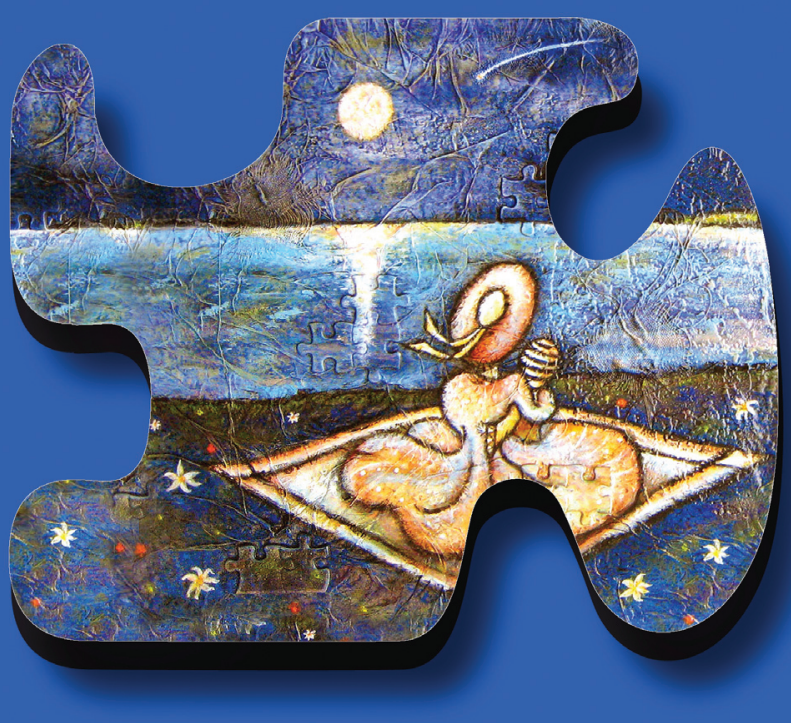


THE ROLE OF ASTRONOMY IN SOCIETY AND CULTURE

IAU SYMPOSIUM No. 260

COVER ILLUSTRATION

This is an adaptation created by Emmanuel Vergnaud, based on the original painting by Guellen (see page 286) to illustrate a book on astronomy for children.

Credit: Emmanuel Vergnaud and Guellen, reproduced with the permission of the artists. 


\title{
IAU SYMPOSIUM PROCEEDINGS SERIES 2009 EDITORIAL BOARD
}

\author{
Chairman \\ I.F. CORBETT, IAU Assistant General Secretary \\ European Southern Observatory \\ Karel-Schwarzschild-Strasse 2 \\ D-85748 Garching-bei-München \\ Germany \\ icorbett@eso.org \\ Advisers \\ K.A. VAN DER HUCHT, IAU General Secretary,
}

SRON Netherlands Institute for Space Research, Utrecht, the Netherlands

E.J. DE GEUS, Dynamic Systems Intelligence B.V., Assen, the Netherlands

U. GROTHKOPF, European Southern Observatory, Germany

M.C. STOREY, Australia Telescope National Facility, Australia

Members

IAUS260

DAVID VALLS-GABAUD, GEPI - Observatoire de Paris, 92195 Meudon, France IAUS261

S. A. KLIONER, Dresden Technical University, 01062 Dresden, Germany IAUS262

G. R. BRUZUAL, CIDA, 5101-A Merida, Venezuela

IAUS263

J. A. FERNANDEZ, Depto. Astronomia, 11400 Montevideo, Uraguay IAUS264

A. KOSOVICHEV, Stanford University, Stanford, CA 94305-4085, USA IAUS265

K. CUNHA, NOAO, La Serena, Chile

IAUS266

R. DE GRIJS, University of Sheffield, Sheffield, UK

IAUS267

B. PETERSON, Ohio State University, Columbus, OH 43219, USA

IAUS268

C. CHARBOnNEL, Geneva Observatory, 1290 Sauverny, Switzerland 
INTERNATIONAL ASTRONOMICAL UNION

UNION ASTRONOMIQUE INTERNATIONALE

International Astronomical Union

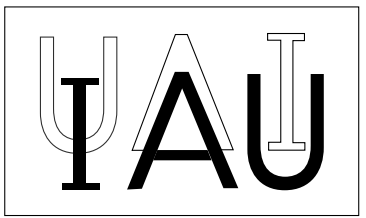

\section{THE ROLE OF ASTRONOMY IN SOCIETY AND CULTURE}

PROCEEDINGS OF THE 260th SYMPOSIUM OF THE INTERNATIONAL ASTRONOMICAL UNION HELD AT THE UNESCO HEADQUARTERS, PARIS, FRANCE JANUARY 19-23, 2009

Edited by

DAVID VALLS-GABAUD

CNRS, Observatoire de Paris, France

and

ALEXANDER BOKSENBERG

Institute of Astronomy, University of Cambridge, United Kingdom 
CAMBRIDGE UNIVERSITY PRESS

The Edinburgh Building, Cambridge CB2 2RU, UnitedKingdom

40 West 20th Street, New York, NY 10011-4211, USA

10 Stamford Road, Oakleigh, Melbourne 3166, Australia

(C) International Astronomical Union 2011

This book is in copyright. Subject to statutory exception and to the provisions of relevant collective licensing agreements, no reproduction of any part may take place without the written permission of the International Astronomical Union.

First published 2011

Printed in the United Kingdom at the University Press, Cambridge

Typeset in System $\mathrm{HT}_{\mathrm{EX}} 2_{\varepsilon}$

A catalogue record for this book is available from the British Library

Library of Congress Cataloguing in Publication data

ISBN 9780521764773 hardback

ISSN 1743-9213 


\section{In memoriam Baruch S. Blumberg (1925-2011)}




\section{Table of Contents}

Preface $\ldots \ldots \ldots \ldots \ldots \ldots \ldots \ldots \ldots \ldots \ldots \ldots \ldots \ldots \ldots \ldots \ldots \ldots \ldots \ldots \ldots \ldots \ldots \ldots$

Organizing committee $\ldots \ldots \ldots \ldots \ldots \ldots \ldots \ldots \ldots \ldots \ldots \ldots \ldots \ldots \ldots \ldots$

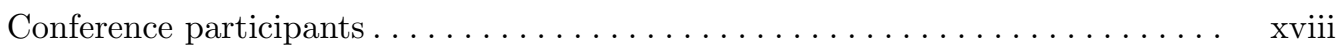

Welcome Address by the Director General for Natural Sciences at UNESCO . . . 1

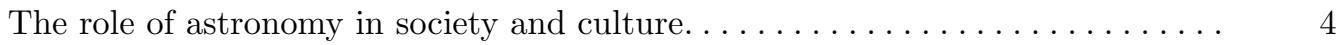

D. Valls-Gabaud \& A. Boksenberg

\section{Setting the context}

Astronomical exploration and the public imagination $\ldots \ldots \ldots \ldots \ldots \ldots$

B.S. Blumberg

Perspectives on our cosmic habitat. . . . . . . . . . . . . . . M.J. Rees

The growth of astrophysical understanding . . . . . . . . . . . . .

M. Harwit

The Big Bang, modern cosmology and the fate of the Universe: impacts upon

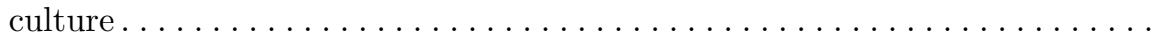

L.M. Krauss

\section{Astronomy in the cultures, and the culture of astronomy}

The astronomy of Aboriginal Australia . . . . . . . . . . . . . . . R.P. Norris \& D.W. Hamacher

The African Cultural Astronomy project.................. J.O. Urama \& J.C. Holbrook

Scriptures, science and mythology: Astronomy in Indian cultures.......... R. Kochhar

The relation of Babylonian astronomy to its culture and society. . . . . . . . H. Hunger

In search of cosmic order: Astronomy and culture in Ancient Egypt . . . . . . .

J.A. Belmonte

Astronomy and its role in ancient Mesoamerica

I. $\breve{S p r a j c}$

Some notes on the Inka constellations

E. Pacheco, S. Flores \& E. Salazar 
Connecting Heaven and Man: The role of astronomy in ancient Chinese society

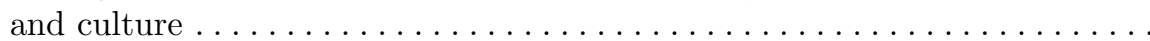

X. Sun

Ancient Chinese constellations

J. $X u$

Orientations of dolmens in Western Europe

M. Hoskin

The significance of the Sun, Moon and celestial bodies to societies in the Carpathian basin during the Bronze Age . . . . . . . . . . . . . . . . . E. Pásztor

The Antikythera Mechanism: The oldest mechanical universe in its scientific milieu X. Moussas

Islamic reception of Greek astronomy G. Saliba

Folk astronomy in Omani agriculture. 166 H. Nash \& D.A. Agius

Kepler, Galileo and the birth of modern astronomy

O. Gingerich

Early dynamical world models: A historical review. . H. Kragh

Cosmology between two wars. Einstein's revolution and alternative models of the Universe. . . . . . . . . . . . . . . . . . . . . . .

A. Curir

Adjusting Astronomical Practices : The "Carte du Ciel", the democratic rules and the circulation of opinions at the end of the 19 th century $\ldots \ldots \ldots \ldots \ldots$ J. Lamy

The creation of the International Astronomical Union as a result of scientific diplo-

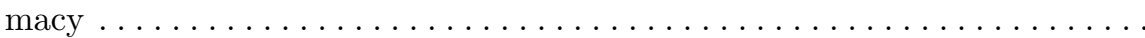

\section{A. Saint-Martin}

Sky observation and mythology: Paths to an astronomical culture .........

V.A. Alencar

The question "Are we alone?" in different cultures $\ldots \ldots \ldots \ldots \ldots \ldots \ldots$ J. Schneider

The naming of minor planets: multicultural relationships $\ldots \ldots \ldots \ldots \ldots \ldots$ J.-C. Merlin

From Ancient to Modern: The role of astronomy as a cultural experience ...... M. Austin

Cultural heritage of astronomical observatories. . . . . . . . . . . . . . . . G. Wolfschmidt

Bosscha Observatory: Challenges as a scientific heritage of astronomy in Indonesia 235 P. Epifania \& E. S. Mumpuni 


\section{Astronomy and the arts}

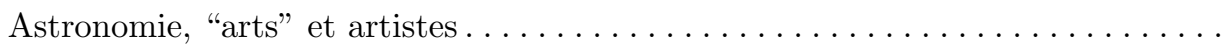

S. Débarbat

Science, art and geometrical imagination

J.-P. Luminet

From Giza to the Pantheon: astronomy as a key to the architectural projects of

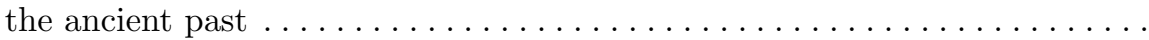

G. Magli

Imagine a universe: An artist's take on astronomy

M. Abbozzo

Art and astronomy: my personal experience

Guellen

A Universe on which to dwell

M. Atkinson

The sky entities as represented in African literature.

E.N. Urama

Hebrew names of the planets

S. Zucker

Hobbits, Hogwarts, and the Heavens: The use of fantasy literature and film in

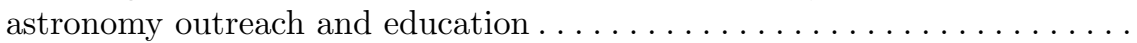

K. Larsen

Desire of stars - poems

D. Benest

The cosmology of Edgar Allan Poe. .

A. Cappi

Astronomy and astronomers in Jules Verne's novels. . . . . . . . . . . .

J. Crovisier

On the telescopes in the paintings of Jan Brueghel the Elder ...........

P. Molaro \& P. Selvelli

Michelangelo, Copernicus and the Sistine chapel

V. Shrimplin

The worldwide impact of Donati's comet on art and society in the mid-19th century

A. Gasperini, D. Galli \& L. Nenzi

A palace for astronomy in Buenos Aires

A. Gangui

TWAN: The World at Night

B.A. Tafreshi

The harmony of the spheres from Pythagoras to Voyager . .

D. Proust 
Astronomy in Brazilian music, literature and poetry $\ldots \ldots \ldots \ldots \ldots \ldots$

R.R. de Freitas Mourão

\section{The social impact of astronomy}

Is astronomy useful for societies? . . . . . . . . . . . . . . . .

J. Audouze

How, precisely, can astronomy be of benefit to anyone? ...........

B.J.T. Jones

The decline of natural sciences in the culture of mass media

C. Elías

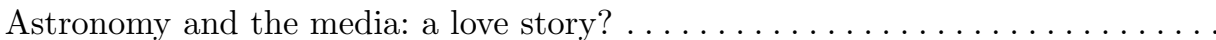
H.M.J. Boffin

Public perception of astronomers: Revered, reviled and ridiculed . . . . . . . M.J. West

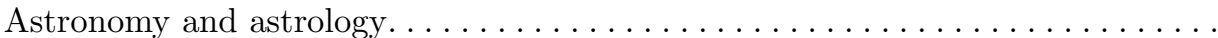
P. Zarka

Dispelling superstitions in Nepalese society with astronomy R. Shah

The role of astronomy and space sciences in Arab societies and cultures ....... H.M.K. Al-Naimiy

Astronomers without borders M. Simmons

The magnificent night sky — why it must be protected from light pollution ..... R.J. Wainscoat

Starlight: a common heritage $\ldots \ldots \ldots \ldots \ldots \ldots \ldots \ldots \ldots \ldots \ldots$ C. Marin

Radio quiet, please! protecting radio astronomy from interference . . . . . . . 457 W. van Driel

Planetariums, theatres of the Universe.

A. Acker

From a closed world to the infinite Universe: Astronomy in prisons . . . . . . . . . 475 D. Briot

Astronomy outreach in hospitals and retirement homes $\ldots \ldots \ldots \ldots \ldots \ldots$ R. Courtin

A dictionary of astronomy for the French Sign Language (LSF) . . . . . . . . 483 D. Proust, D. Abbou \& N. Chab

Astronomical activities with disabled people.................

A. Ortiz-Gil, P. Blay, A. T. Gallego Calvente, M. Gómez, J. C. Guirado, M. Lanzara \& S. Martínez Núñez 
The UNESCO Thematic Initiative on Astronomy and World Heritage . . . . . . .

A.P. Sidorenko

MENSURA CAELI: Territory, Town, Architectures, Tools . . . . . . . . . . . .

M. Incerti \& E. Antonello

The astronomical observatory of the University of Havana: A project for its reha-

bilitation as a center for science popularisation . . . . . . . . . .

M. de la Guardia Durán

Reconstructing the astronomical heritage .

P. Planesas

Astronomy at the service of the Islamic society

I.M. Fernini

Introducing astronomy into Mozambican society $\ldots \ldots \ldots \ldots \ldots \ldots$

V.A.R.M. Ribeiro, C.M. Paulo, A.M.A.R. Besteiro, H. Geraldes,

A.M. Maphossa, F.A. Nhanonbe \& A.J.R. Uaissine

Astronomy in the society and culture of Estonia

L. Leedjärv

Searching for a "black sky" in the Andes Mountains: A migratory process and identity formation of a Japanese astronomer in Peru . . . . . . . . . . . . . N. Kato-Nitta

\section{Astronomy as a tool for development and technologies}

Astronomy for international development

G. Miley

Astronomy, technology development and industry

L. Vigroux

Virtual Acoustic Space: Space perception for the blind

L.F. Rodríguez-Ramos

What astronomy can bring to the hi-tech party

J.E. Jones

Techies, thinkers and tinkerers: Why CFHT became a world-class telescope ....

L. Bryson

Astronomy for African development.

K. Govender

Astronomy in post-apartheid South Africa

P.A. Whitelock

Astronomy and political theory 


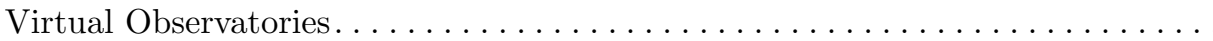

F. Genova

The World's first global telescope network at your fingertips

E.L. Gomez \& H.L. Gomez

An astronomical observatory for Peru $\ldots \ldots \ldots \ldots \ldots \ldots \ldots \ldots \ldots \ldots \ldots \ldots \ldots \ldots$

J. Quintanilla del Mar, B. Sicardy, V. Ayma Giraldo \& V.R. Aguilar Callo

\section{Education and public understanding of astronomy}

Educational aspects of cosmology: Global Cosmology Teachers Academy . . . . . G.F. Smoot

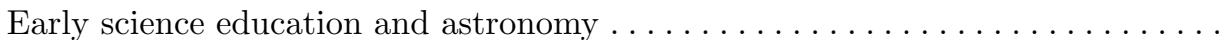

D. Wilgenbus \& P. Léna

International Schools for Young Astronomers and Teaching for Astronomy Development: two programmes of the IAU $\ldots \ldots \ldots \ldots \ldots \ldots \ldots \ldots \ldots \ldots \ldots \ldots$ M. Gerbaldi, J.-P. DeGreve \& E. Guinan

Universe Awareness: Inspiring young children around the world . . . . . . . . C.J. Ödman

Conveying astronomy to the public J. Fierro

No "explosion" in Big Bang cosmology: teaching kids the truth of what cosmologists

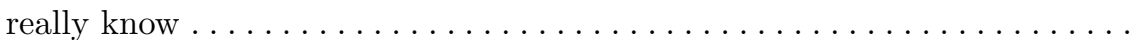

A. Gangui

Black Holes, Quasars, Blazars, and all that... How to explain them to a lay audi-

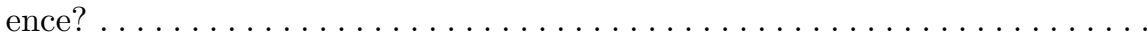

H. Hamidani \& J. Mimouni

Status of astronomy at Mbarara University of Science and Technology, Uganda . S. Anguma \& E. Jurua

Improving the scientific literacy of Aboriginal students through astronomy..... R. Bhathal

Astronomical education in Mongolia 685

A. Dulmaa, R. Tsolmon, Ch. Lkhagvajav, Sh. Jargalsuren, B. Bayartungalag \& M. Zaya

Astronomy in additional education in Kazakhstan $\ldots \ldots \ldots \ldots \ldots \ldots \ldots$ 690 V. Zagainova

Astronomy education and scientific schools in Ukraine 696 Y.S. Yatskiv \& I.B. Vavilova

Astronomical education in Tajikistan. Project TAJASTRO 704 K.I. Ibadinov \& A.A. Rahmonov 
Non-formal education in astronomy: The experience of the University of Carabobo N. Falcón

Teaching astronomy and astrophysics with Hands-On-Universe and SalsaJ: stars,

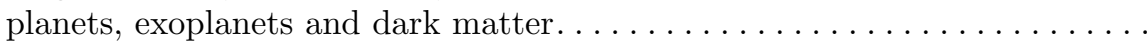
S. Faye \& M. Faye

The International Astronomy Olympiad M.G. Gavrilov

"Nuits des étoiles" events (1991-2008) and their impact on the French astronomical

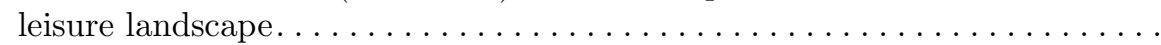
O. Las Vergnas \& E. Piednoël

"Astrophysique sur Mesure", E-learning in astronomy and astrophysics . . . . . . B. Mosser, A. Delsanti, D. Guillaume, C. Balança \& C. Balkowski

Popularizing science through astronomy, an Algerian experience in grassroot activism and its academic spin-off $\ldots \ldots \ldots \ldots \ldots \ldots \ldots \ldots \ldots \ldots \ldots \ldots \ldots \ldots$ J. Mimouni

Astronomy and space outreach new requirements for a new generation ....... K. Nolan

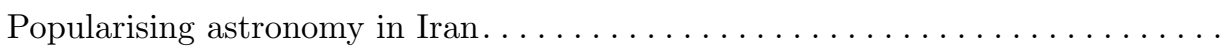
B.A. Tafreshi

STAR WEEK: A successful outreach campaign in Japan. . . . . . . . . . . . . 758 J. Watanabe

Using videoconferencing for elementary/secondary teacher professional develop-

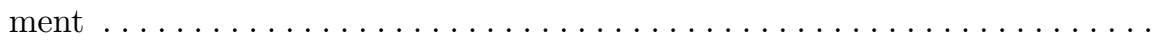

M. K. Hemenway, M. Wetzel, M. Rood, C. Roberts-Gray \& S. Preston

Some remarks on a current study involving preservice elementary teachers and some basic astronomical phenomena. . . . . . . . . . . . . . A. Gangui, M. Iglesias \& C. Quinteros

Art exhibition "Astronomical Inspirations"

Author index 776

Subject index 778

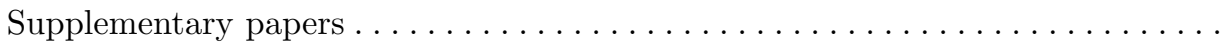




\section{Preface}

To any person with even the vaguest idea of the nature of scientific evidence, such beliefs as those of astrologers are of course impossible. But so are most of the beliefs upon which governments are based, such as the peculiar merit of persons living in a certain area, or of persons whose income exceeds a certain sum. It would not do to teach people to reason correctly, since the result would be to undermine these beliefs. If these beliefs were to fade, mankind might escape disaster, but politicians could not. At all costs, therefore, we must be kept stupid.

Bertrand Russell (1932)†

Il faut donc qu'à l'effort de construire la science nous joignons celui de la rendre accessible, de manière que l'humanité poursuive sa marche [...]

Paul Langevin (1946)

Bertrand Russell famously discussed the divorce between science and culture back in 1957 (upon receiving UNESCO's Kalinga Prize), and warned us of its dire consequences for the survival of humankind. Since then, the gap has perhaps widened even more and yet, at the same time, our societies have never been so interested in scientific activities and in particular by astronomy, being increasingly aware of the tremendous progress made over the past decades. Astronomers are well aware of their social responsibilities as scientists, and engage in a wide spectrum of activities to bring astronomy to a larger public within their cultures, and in some cases around the planet. Yet light pollution prevents an increasingly larger fraction of people to watch the sky and be aware of the beauty of astronomical phenomena, while artists continue to be inspired by them. The public success of well-publicised discoveries -and space missions- should not however mask some infamous overstatements, such as the case of the NASA Mars meteorite, which may question the science communication tools that have been used, following the wise advice of Russell and Langevin.

What is, therefore, the precise role of astronomy within our societies? How may astronomers influence -and are affected by- the different cultures they live in? Can they help the development of societies beyond the purely intelectual realm? How is astronomy perceived by the different actors in our societies, from the general public to governmental agencies through artists and students? Can astronomers help reducing the waning interest that the younger generations of students seem to feel about science studies? What are the current efforts in astronomy education across the planet, especially in developing countries? Can we reach in better ways impaired or confined communities? Can collaborations be improved with amateurs, with further joint cooperations, along with those offered by planetaria world-wide or indeed the public at large? How can astronomical

$\dagger$ "On astrologers", Hearst columns, 28 september 1932.

$\ddagger$ "La pensée et l'action", talk delivered on May 10, 1946, and published in Bull. Mensuel d'Inf. de l'Union française universitaire, May 1947, p. 3. 
societies and science academies help governmental agencies in deciding the policies that will affect our societies?

These are some of the questions that were addressed at the Symposium, as it became a forum to discuss the activities and efforts which continue to take place world-wide -besides the ones that were organised for IYA 2009- and ponder on the way to improve the multiple relations that astronomy has within our societies, our diverse cultures and educations.

By inviting many representatives of the different initiatives and activities developed in all these aspects, we seeked to provide a detailed panorama so that we can focus on the efforts that remain to be made. Overall, this conference brought together many actors who succeed in ensuring that astronomy is present -at all levels- in Education, Society and Culture worldwide. These are precisely the aims of UNESCO, and it is only right that this Symposium took place at their Headquarters in Paris during the International Year of Astronomy.

The conference was rather unique in a number of points:

- This was the first time since 1919, when the International Astronomical Union was founded $\dagger$, and since 1949, when the very first "IAU symposium" was held, that a Symposium has been devoted to a series of topics which, while not being strictly scientific, are of such an importance that they cannot be disregarded any longer, not only for our discipline, but indeed to an increasingly wider fraction of our societies. While the proposal met a strong opposition in some quarters, the wiser support of various IAU Commissions and Divisions eventually prevailed.

- The Scientific Organising Committee obviously included non-professional astronomers, but their number was unfortunately limited both by IAU rules and by practical considerations. While women constituted $38 \%$ of the attendance, we intended to achieve parity in the chairs of the 26 sessions the Symposium was divided into but only reached, unfortunately, the same proportion. We gratefully acknowledge the help provided by the chairpersons of the sessions: A. Acker (France), O. Alvarez (Cuba), J. Audouze (France), E. Antonello (Italy), C. Balkowski (France), J. Beckman (Spain), J.A. Belmonte (Spain), H. Boffin (Germany), C. Cesarsky (Germany), R. Courtin (France), C. del Puerto (Spain), R. Ferlet (France), J. Fierro (México), B. García (Argentina), M. Gerbaldi (France), O. Gingerich (USA), B.J.T. Jones (UK), L.M. Krauss (USA), P. Morel (France), R. Norris (Australia), D. Proust (France), C. Ruggles (UK), S. Torres-Peimbert (México), P. Whitelock (South Africa), and J. Zhu (China). The attendance, nearing 400 people, included two Nobel Prize winners (B.S. Blumberg and G.F. Smoot), artists, historians, amateurs, teachers, journalists, planetarium directors, students and astronomers, a good representative sample of people who convey astronomy to different publics in many different ways.

- A key part of the symposium was the art exhibition, "Astronomical inspirations", hosted in the Salles Miró of the UNESCO Headquarters, featuring sculptures, paintings, photographs, videos and a reproduction of the Antikythera mechanism. Artists came from 26 countries, from Mongolia to Hungary, from Australia to Argentina, through Romania or Korea. To ensure a maximal number of visitors, we inaugurated the exhibition the week before the conference, so that participants to the Inaugural Opening Ceremony of the International Year of Astronomy could also experience this unique event. Besides observations of the Sun and Venus from the main patio of UNESCO, several other activities took place:

$\dagger$ Brussels, 18-28 July 1919, see A. Blaauw (1994) History of the IAU, the birth and first half-century of the International Astronomical Union (Dordrecht: Kluwer). 
- a performance by the Arcadia Theatre (www .theatrearcadia.com) of Euripides' Medea with actresses Katerina Paliou and Lydia Palas, and based on the translation into English by G. Theodorides, with a scenography by G. Ziovas, costume designer Ariadne Mackinnon and music by Effie Ratsou;

- the screening of the film 400 years of the telescope by Kris Koening (see www. 400years.org) at the Centre National de la Recherche Scientifique (CNRS) Headquarters;

- two astronomical walks through the Quartier Latin to visit sundials and the Perrault building at Observatoire de Paris, thanks to members of the Sundial Section of the Société Astronomique de France;

- a virtuoso piano and organ recital in the Salle Marcel Dupré (Meudon), by Dominique Proust;

○ the screening of Paul Devlin's BLAST! (see blastthemovie.com);

○ the stunning audiovisual prepared by the TWAN collaboration, projected on the Main Foyer at UNESCO;

- Hawaiian Starlight (www . cfht . hawai . edu/Hawai ianStarlight) by Jean-Charles Cuillandre and Astronomical Pictures of an Exhibition (svl.adlerplanetarium. org/videosuites/APE) by José-Francisco Salgado featured in Session 9 (Astronomy and the Arts - II: From architecture to films).

- Another pioneering initiative, for an IAU Symposium, was the live transmission of the morning plenary talks and some afternoon sessions, which were recorded, archived and made available at the website of Strasbourg's University CANAL C2:

http: //canalc2.u-strasbg.fr/video.asp?idVideo=8428

We thank the CANAL C2 and the UNESCO teams for a superb coordination and montage. We hope this will set an example for future symposia, as the number of attendees is likely to decrease in a carbon-conscious global society.

- Last, but certainly not least, we were acutely aware of the difficult situation of hosting students and astronomers from developing countries in one of the most expensive capitals of the planet. Not only the LOC provided -as many as we possibly could within the budget- with generous grants and/or waiving the fees, but we also organised -with the key help of Suzanne and Michel Faye- a network of hosting familes in Paris which welcomed at their homes, free of charge, participants who could not afford hotels. This setup worked remarkably well, the hosting families learning about astronomy in other countries, and the participants enjoying a real experience of living with a French family. Let us hope this precedent will also set a new standard in international conferences.

This volume collects most of the written versions of the talks given at the symposium, but unfortunately some papers were not received. Besides making corrections and ensuring the uniformity of the notation used, the editors checked that each of the over 1900 bibliographic references and websites were correct at the time of publication. The publication was delayed by a number of factors but it is nevertheless hoped that the shelf life of this volume will be longer than average, and will reach a wide readership.

David Valls-Gabaud, SOC chair Paris and Cambridge, May 2010 


\section{THE ORGANIZING COMMITTEE}

\section{Scientific}

Jean Audouze (France)

Juan A. Belmonte (Spain)

Beatriz Barbuy (Brasil)

Alec Boksenberg (UK)

Catherine Cesarsky (Germany)

Dennis Crabtree (Canada)

Walter Erdelen (UNESCO)

Roger Ferlet (France)

Martin George (Australia)

Owen Gingerich (USA)

Georges Haddad (UNESCO)

Toshihiro Handa (Japan)

\section{Local}

Brigitte Bourdon (Obs. Paris)

Yolanda Berenguer (UNESCO)

Anne Candau (UNESCO)

Régis Courtin (Obs. Paris)

Suzanne Faye (Lycée Chaptal, Paris)

Sabine Kimmel (Obs. Paris)

Francis Michel-Zamora (UNESCO)
Lawrence M. Krauss (USA)

Edwin C. Krupp (USA)

George Miley (The Netherlands)

Philippe Morel (France)

Carl Pennypacker (USA)

Dominique Proust (France)

Martin J. Rees (UK)

Magda Stavinschi (Romania)

Silvia Torres-Peimbert (México)

David Valls-Gabaud (France, Chair)

Patricia Whitelock (South Africa)

Zhao Gang (China)

Jacqueline Pluet (Obs. Paris)

Dominique Proust (Obs. Paris, Chair)

Lucía Seoane (Obs. Paris)

Sylvestre Taburet (Obs. Paris)

Pierre Toupet (Obs. Paris)

David Valls-Gabaud (Obs. Paris)

Emmanuel Vergnaud (Obs. Paris)

\section{Acknowledgements}

The symposium was supported by IAU Divisions IV (Stars) and XII (Union-wide activities), and by IAU Commissions 5 (Documentation and astronomical data), 16 (Physical study of planets \& satellites), 22 (Meteors, meteorites \& interplanetary dust), 26 (Double and multiple stars), 41 (History of astronomy), 42 (Close binary stars), 46 (Astronomy education and development), 50 (Protection of existing \& potential observatory sites), and 55 (Communicating astronomy with the public).

The Local Organising Committee operated under the auspices of

Observatoire de Paris and UNESCO.

Funding by

International Astronomical Union,

Académie des Sciences, Paris,

Institut National des Sciences de l'Univers (INSU/CNRS),

Observatoire de Paris,

UNESCO,

and

Région Ile-de-France,

is very gratefully acknowledged. 


\section{Participants}

Margherita Abbozzo, Italy

Daniel Abou, France

Agnes Acker, France

María Luisa Aguila, Peru

Hamid Al-Naimiy, United Arab Emirates

Aram Alecian, France

Christina Alepi, Greece

Oscar Alvarez Pomares, Cuba

Victor Alves Alencar, Brazil

Adeline André, France

Ivan L. Andronov, Ukraine

Simon Anguma Katrini, Uganda

Edwin A. Antiche Garzón, Venezuela

Erika L. Antiche Garzón, Venezuela

Elio Antonello, Italy

Gonzalo Argandona, Chile

Jean-Eudes Arlot, France

Javier Armentia, Spain

Marea Atkinson, Australia

Brigitte Aubert Velasco, Peru

Jean Audouze, France

Margaret Austin, New Zealand

Víctor Ayma Giraldo, Peru

Paul Baki, Kenya

Chantal Balkowski, France

George Bampasidis, Greece

Wladimir Banda Barragán, Ecuador

Charles Barclay, United Kingdom

John Beckman, Spain

Jocelyn Bell Burnell, United Kingdom

Juan Antonio Belmonte, Spain

Leopoldo Benacchio, Italy

Daniel Benest. France

Zouhair Benkhaldoun, Morocco

Yolanda Berenguer, UNESCO

Olivier Berné, Spain

Jérôme Berti, Switzerland

Ragbir Bhathal, Australia

Suresh Bhattarai, Nepal

Nicolas Biver, France

Sophie-Anne Blondin, Canada

Baruch S. Blumberg, USA

Caterina Boccato, Italy

Henri Boffin, Germany

Alec Boksenberg, United Kingdom

Amy Bonsor, United Kingdom

Jean-Louis Bougeret, France

Elodie Boukobza, France

Chantal Bourdet, France

Brigitte Bourdon, France

Jean-Claude Bourdon, France

Catherine Bourgois, France

Lionel Bret. France

Micaela Brotons Lopez, Spain

Liz Bryson, USA

Maria Carla Calcioni, Italy

Nicholas Campion, United Kingdom

Anne Candau, UNESCO

Alberto Cappi, Italy

Julio A. Carballo-Bello, Spain

Michel Cassé, France

Juan Alejandro Castillo, Argentina

Cynthia Celebre, Philippines

Gjore Cenev, FYR of Macedonia

María Luisa Cerdeño, Spain

Catherine Cesarsky, France

Catherine Cesarsky,
Nasro Chab, France

Stéphane Charbonel, France

Stefano Ciroi, Italy

Alain Cirou, France

Frances Clynes, Ireland

François Colas, France

Virginia Corless, United Kingdom

Vincent Coudé du Foresto, France

Régis Courtin, France

Thierry Courvoisier, Switzerland

Dennis Crabtree Chile

Carolin Craw ford, United Kingdom

Lynn Crighton-Lyon, France

Jacques Crovisier, France

Istvan Csepeli, Hungary

Jean-Charles Cuillandre, USA

Anna Curir, Italy

M. Chantale Damas, USA

Doris Daou, USA

Gilles Dawidowicz, France

Ronaldo Rogério De Freitas Mourão, Brazil

Monica De la Guardia Durán, Cuba

Suzanne Débarbat, France

Carmen Del Puerto, Spain

Lauriane Delaye. France

Marc Delcroix, France

Christine Delrieux, France

Christine Delrieux, France

Pascal Descamps, France

Frédéric Devevey, France margheritaabbozzo@yahoo.com daniel.abbou@neuf.f acker@astro.u-strasbg.fr ml_aguilarh@yahoo.es alnaimiy1@gmail.com georges.alecian@obspm.f knoulp@gmail.com oscar@citma.cu vitoralen@gmail.com vitoralen@gmail.com
adelinandre@gmail.com tt_ari@ukr.net

simonanguma@yahoo.com antichegarzon@hotmail.com erika_antiche@hotmail.com elio.antonello@brera.inaf.it gargando@eso.org arlot@imcce.fr

javarm@pamplonetario.org

Marea.Atkinson@unisa.edu.au

britauve@hotmail.com audouze@iap.fr austinme@xtra.co.nz vaymagiraldo@hotmail.com paulbaki@gmail.com

chantal.balkowski@obspm.fr gbabasid@phys.uoa.gr wlady.bsc@gmail.com ceb@astro.ox.ac.uk jeb@iac.es

jocelyn@astro.ox.ac.uk jba@iac.es

leopoldo.benacchio@oapd.inaf.it benest@oca.eu zouhair@ucam.ac.ma y.berenguer@unesco.org olivier.berne@gmail.com sir_berti@hotmail.com r.bhathal@uws.edu.au

chikursharma@gmail.com nicolas.biver@obspm.fr

Sophie-Andree.Blondin@radio-canada.ca

Baruch.Blumberg@fccc.edu caterina.boccato@oapd.inaf.it hboffin@eso.org boksy@ast.cam.ac.uk abonsor@ast.cam.ac.uk

jean-louis.bougeret@obspm.fr elodieboukobza@yahoo.fr durbans@club-internet.fr brigitte.bourdon@obspm.fr jcbzee@club-internet.fr

catherine.bourgois@obspm.fr lbret@free.fr miqui@telefonica.net bryson@cfht.hawaii.edu $\mathrm{m}$ ariacarlacalcioni@gmail.com n.campion@lamp.ac.uk a.candau@unesco.org

alberto.cappi@oabo.inaf.it jacb@iac.es casse@iap.fr juanalejandrocastillo@gmail.com cynthia_celebre@yahoo.com $\mathrm{mkc} @ \mathrm{mt} . n \mathrm{et} . \mathrm{mk}$ mluisac@ghis.ucm.es catherine.cesarsky@cea.fr nasreddine.chab@cnam.fr scharbonnel949@gmail.com stefano.ciroi@unipd.it

alain.cirou@cieletespace.fr

frances.clynes@gmail.com colas@imcce.fr

virginia.corless@alum.mit.edu

vincent.foresto@obspm.fr regis.courtin@obspm.fr

thierry.courvoisier@unige.ch dcrabtree@gemini.edu csc@ast.cam.ac.uk lvalyon@hotmail.com

jacques.crovisier@obspm.fr emipasztor@freemail.hu jcc@cfht.hawaii.ed u curir@oato.inaf.it

chantale_damas@yahoo.com Doris.Daou-1@nasa.gov dawido@ifrance.com mourao@ronaldomourao.com monica@reduniv.edu.cu Suzanne.Debarbat@obspm.fr cpv@iac.es

lauriane.delaye@obspm.fr delcroix.marc@free.fr lcx2608@hotmail.com pascale.demy@av-atelier.de descamps@imcce.fr

frederic.devevey@inrap.fr 
Chiara Di Benedetto, Italy

Tracey Dickens, United Kingdom

Francisco Diego, United Kingdom

Jean-Luc L. J. Dighaye, Germany

Pauline Pearl Divinagracia, Philippines

Gilles Dodray, France

Rosa Doran, Portugal

Alain Doressoundiram, France

Patrick Duchemin, France

Altangerel Dulmaa, Mongolia

Daniel Egret, France

Carlos Elias, Spain

Hoda S. Elmikaty, Egypt

Marta Entradas, United Kingdom

Priscilla Epifania, Indonesia

Walter Erdelen, UNESCO

Jean-Michel Faidit, France

Nelson Falcon, Venezuela

Suzanne Faye, France

Michel Faye, France

Roger Ferlet, France

Elias Fernini, United Arab Emirates

Alain Ferreira, France

Julieta Fierro, Mexico

Nahiely Flores, Mexico

Soraya Flores, Peru

Morgane Fortin, France

Patrick Fuentes, France

José Funes, Vatican

Daniele $\mathbf{G a l l i}$. Italy

Daniel Gambis. France

Alejandro Gangui, Argentina

Beatriz García, Argentina

William Garnier, Chile

Antonella Gasperini, Italy

Mikhail Gavrilov, Russia

Françoise Genova, France

Michèle Gerbaldi, France

Andrei-Dorian Gheorghe, Romania

Nikos Giannopoulos, Greece

André Gilloire, France

O wen Gingerich, USA

Stéphanie Godier, France

Vira

John Goldsmith, Australi

Edward Gomez, United Kingdom

Haley Gomez, United Kingdom

Andrée Gotteland, France

Martine Gourgeot France

Kevindran Govender, South Africa

Attila Grandpierre, Hungary

Valentin Grigore, Romania

Monique Gros, France

Frédéric Guérin, France

Sandrine Guerlet, France

Hélène Guiziou, France

Agustinus Gunawan Admiran. Indonesia

Patricio Guzmán, Chile

Georges Haddad, UNESCO

Andreas Haenel, Germany

Hamid Hamidani, Algeria

Peter Hargrave, United Kingdom

Laura Hart, Argentina

Martin Harwit, USA

Mary Kay Hemenway, USA

Martin Hendry, United Kingdom

Xavier Hernández, Mexico

Hector Hernández Toledo, Mexico

Taufiq Hidayat, Indonesia

Jarita Holbrook, USA

Michael Hoskin, United Kingdom

Chia-Ling $\mathbf{H u}$, Taiwan

Hermann Hunger, Austria

Stephanie Hunt, United Kingdom

Khursandkul Ibadinov, Tajikistan

Subhon Ibadov, Tajikistan

Manuela Incerti, Italy

Doina Ionescu, Romania

Md.Biozid Jessorey, Bangladesh

Carmen Gloria Jiménez, Chile

Noorali Jiwaji, Tanzania

Isabelle Joncour. France

Bernard Jones, United Kingdom

Janet Jones, United Kingdom

Marc Joos, France

Eric Josselin, France

$\mathrm{X} u$ Junjun, Chin

Edward Jurua, Uganda

Yvonne Kaiser Argentina

Yvonne Kaiser, Argentin
David Kaiser, Argentina

David Kaiser, Argentina

Naoko Kato-Nitta, Japan

Badu Kedar, Nepa

S.O. Kepler, Brazil

Rajesh Kochhar, India

Anne-Lize Kochuyt, Belgium

Dorota Koziel-Wierzbowska, Poland

Helge Kragh, Denmark chiara.dibenedetto@unipd.it tp57@le.ac.uk fd@star.ucl.ac.uk jdighaye@eurastro.de pau2x13@yahoo.com gilles.dodray@numericable.com rosa.doran@ nuclio.pt
alain.doressoundiram@obspm.fr Patrick@duchemin.eu dulmaa@num.edu.mn president.observatoire@obspm.fr carlos.elias@uc3m.es

hoda.elmikaty@bibalex.org m.entradas@ucl.ac.uk

priscilla_epifania@yahoo.com w.erdelen@unesco.org

faiditmontpellier@yahoo.fr nelsonfalconv@gmail.com m faye $2 @$ wanadoo.fr mfaye $2 @$ wanadoo.fr ferlet@iap.fr

ifernini@uaeu.ac.ae

alainferreira@free.fr

julieta@astroscu.unam.mx nahiely@astroscu.unam.mx soryta18@hotmail.com fortin@iap.fr camfuentes@yahoo.fr jfunes@specola.va galli@arcetri.astro.it

daniel.gambis@obspm.fr gangui@iafe.uba.ar

beatrizgarciautn@gmail.com wgarnier@alma.cl gasperi@arcetri.astro.it gavrilovissp@list.ru

genova@astro.u-strasbg.fr gerbaldi@iap.fr

vali.grigore@gmail.com giannopoulos.nikos@gmail.com andre.gilloire@wanadoo.fr ginger@cfa.harvard.edu

stephanie.godier@gmail.com godunova@mao.kiev.ua

John.Goldsmith.MSc@gmail.com egomez@lcogt.net

haley.gomez@astro.cf.ac.uk goandree@numericable.fr martine.gourgeot@gmail.com $\mathrm{kg} @$ saao.ac.za grandp@iif.hu

vali.grigore@gmail.com gros@iap.fr

frederic.guerin@obspm.fr sandrine.guerlet@obspm.fr guellen@voila.fr

gun_agustinus@yahoo.com

atacama $05 @$ wanadoo.fr g.haddad@unesco.org ahaenel@uos.de

hamidanihamid@yahoo.fr

p.hargrave@astro.cf ac.uk

hart_visual@yahoo.com.ar harwit@verizon.net

marykay@astro.as.utexas.edu martin@astro.gla.ac.uk xavier@astroscu.unam.mx

hector@astroscu.unam.mx taufiq@as.itb.ac.id

holbrook@u.arizona.edu

michael.hoskin@ntlworld.com selinehu@phys.ntu.edu.tw hermann.hunger@univie.ac.at shunt@ast.cam.ac.uk ibadinov@mail.ru ibadovsu@yandex.ru

manuela.incerti@unife.it

library@aira.astro.ro biozid99@yahoo.com youhyax@gmail.com ntjiwaji@yahoo.com

ijoncour@obs.ujf-grenoble.fr bernard@astrag.demon.co.uk

janet@astraguard.com marc.joos@obspm.fr

josselin@graal.univ-montp2.fr xjjhhyy@sina.com ejurua@gmail.com

yvonnekaiser@hotmail.com

eldavidmedina@hotmail.com eldavidmedina@hotmail.com
kalinnikova.stacey@gmail.com kato_naoko@soken.ac.jp kedarbadu@yahoo.com kepler@if.ufrgs.br

rkochhar2000@gmail.com anne-lize.kochuyt@planetarium.be eddie@oa.uj.edu.pl

helge.kragh@ivs.au.dk 
Lawrence Krauss, USA

Daniel Kunth, France

Florence Lafitte, France

Astrid Lamberts, France

Jérôme Lamy, France

Marie-France Landréa, France

Kristine Larsen, USA

Olivier Las Vergnas, France

Laurent Laveder, France

MaryBeth Laychak, USA

Jean-Christophe Le Floch, France

Alain Le Gué, France

Laurits Leedjärv, Estonia

Ludovic Lefebvre, France

Dominique Leglu, France

Pierre Léna, France

Jean-François Lestrade, France

Anny-Chantal Levasseur-Regourd, France

Fiallo Lili, Argentina

Constantino Listowski, France

Ericson López, Ecuador

Jean-Pierre Luminet, France

YinZhe Ma. United Kingdom

Tommaso Maccacaro, Italy

Giulio Magli, Italy

Terence Mahoney, Spain

Pauline Maillard, Switzerland

Mponda Malozo, Tanzania

Cipriano Marin, Spain

Irène Marle-Richleacov, France

Eduardo Martín. Spain

David Martínez Delgado. Spain

Madeleine Masle, France

Daniela Mastrangelo, United Kingdom

Gernot Meiser, Germany

Javier Mejuto González, Spain

Jean-Claude Merlin, France

George Miley, The Netherlands

Jamal Mimouni, Algeria

Vincent Minier, France

Félix Mirabel, Chile

Andrej Mohar, Slovenia

Paolo Molaro, Italy

Rodolfo Montez, USA

Philippe Morel, France

Martin Morgan-Taylor, United Kingdom

Catalin Mosoia, Romania

Benoît Mosser, France

Xenophon Moussas, Greece

Tomoya Nagai, Japan

Orlando Naranjo, Venezuela

Harriet Nash, United Kingdom

Faustino Armando Nhanombe, Mozambique

Hyerim Noh, Korea

Kevin Nolan, Ireland

Ray Norris, Australia

Carolina Ödman, The Netherlands

Anouck Ody, France

Pius Okeke, Nigeria

Patrice Okouma, Gabon

Dimitrie Olenici, Romania

Beatriz Ordonez, Argentina

Amelia Ortiz-Gil, Spain

Emel Özcan, Turkey

Mehmet Emin Özel, Turkey

Elluz Pacheco, Peru

Franco Pacini, Italy

Szilvia Pállay, Hungar

Vivien Parmentier, France

Filip Partalovski, FYR of Macedonia

Friedel Pas, Belgium

Marie-Claude Paskoff, France

Emília Pásztor, Hungary

Reza Pazhouhesh, Iran

Antonio Pedrosa, Portugal

Maria Angeles Peña-Guerrero, Mexico

Gerrit Penning, South Africa

Carlton Pennypacker, USA

Enrique Pérez. Spain

Kala Perkins, USA

Jean-Pierre Picat, France

Eric Piednoël, France

Olga Pintado, Argentin

Pere Planesas, Chile

Olga Polyakova, Russia

David Portsmouth, France

Finita Poveda, Spain

Sébastien Prat, France

Robert Priddey, United Kingdom

Dominique Proust, France

Batmyagmar Purevjav. Mongolia

Anna M. Quider, United Kingdom

Juan Quintanilla del Mar, France

Jean-L. Rault, France

Martin J Rees, United Kingdom

Sophie Remy, France krauss@asu.edu

kunth@iap.f

orence@duolafitte.com astrid.lamberts@obspm.fr jerome.lamy@laposte.net marie-france.landrea@obspm.fr o.lasvergnas@cite-sciences.fr laurent.laveder@laposte.net mary@cfht.hawaii.edu

president@astroqueyras.com

alain.legue@wanadoo.f leed@aai.ee

ludovic.lefebvre7@free.fr dleglu@sciences-et-avenir.com pierre.lena@obspm.fr

jean-francois.lestrade@obspm.fr aclr@aerov.jussieu.f lili.fiallo@gmail.com listowsk@iap.fr ericson1@hotmail.com jean-pierre.luminet@obspm.fr yzm20@cam.ac.uk presidenza@inaf.it

Giulio.Magli@polimi.it tjm@iac.es

pauline.maillard@gmail.com mponda2001@yahoo.com

c.marin@unescocan.org

irene.richleacov@laposte.net ege@iac.es ddelgado@iac.es masle@wanadoo.fr aricorte@libero.it

gernot.meiser@av-atelier.de jmejugon@fis.ucm.es jcmerlin@wanadoo.fr

miley@strw.leidenuniv.nl

jamalmimouni@yahoo.com vincent.minier@cea.fr fmirabel@eso.org andrej.mohar@tp-lj.si molaro@oats.inafit molaromat.it

Morel.Philippe@wanadoo.f mart@dmu.ac.uk briefpress@gmail.com benoit.mosser@obspm.fr xmoussas@phys.uoa.gr t.nagai@nao.ac.jp aranjoula@y hoo.com nashalbu@uku.co.uk nashalbu@uku.co.uk
faustino.armando@yahoo.com.br hr@kasi.re.kr knolan@it-tallaght.ie Ray.Norris@csiro.au

carolina.odman@unawe.org anouck.ody@obspm.fr okekepius@yahoo.com okouma@gmail.com dimitrieolenici@hotmail.com beatriz_o_g@yahoo.com.ar amelia.ortiz@uv.es nesemoz@gmail.com me_ozel@hotmail.com elita_p_c@hotmail.com pacini@arcetri.astro.it emipasztor@freemail.hu vparmentier@gmail.com

filipmhz@yahoo.com europe@darksky.org paskoff@club-internet.fr emipasztor@freemail.hu pazhouhesh@fastmail.ca apedrosa@multimeios.pt guerrero@astroscu.unam.mx gpenning @ webmail.co.za pennypacker@lbl.gov eperez@iaa.es quasar9@mac.com jplabo@wanadoo.fr eric.piednoel@afanet.fr olga.pintado@gmail.com pplanesa@alma.cl oleniya@mail.ru

david.portsmouth@orange.fr finita.poveda@yahoo.es sebastien.prat@bredinprat.com

R.S.Priddey@herts.ac.uk dominique.proust@obspm.fr mipasztor@freemail.hu aquider@ast.cam.ac.uk juan.quintanilla@obspm.fr f6agr@orange.fr mjr@ast.cam.ac.uk sofremy@aol.com 
Hélène Reyss, France

Salvador Ribas, Spain

Valeiro A R M Ribeiro, United Kingdom

Susan Riggs, USA

Thapa Rijendra, Nepal

Teodoro Roca Cortés. Spain

César Rodríguez Gordillo, Spain

Gracia Rodríguez-Caderot, Spain

Luis Fernando Rodríguez-Ramos, Spain

A urélie Rousseau, France

Clive Ruggles, United Kingdom

Natalia Ruiz Zelmanovitch. Spain

Pedro Russo, Germany

Georges Saccomani, France

Renate Sachse, France

Sarojiny Saddul-Hauzaree, Mauritius

Arnaud Saint-Martin, France

Julieta R. Salazar Contreras, Mexico

José Francisco Salgado. USA

George Saliba, USA

Mariade Fátima Saraiva, Brazi

Emilio Sassone Corsi, Italy

Yusuke Sato, Japan

Philippe Sauvageot, France

Renaud Savalle, France

Jean Schneider, France

Matthew Schneps, USA

Laurent Schram, France

Nassim Seghouani, Algeria

Rishi K.B.Shah, Nepal

Sweta Shah, The Netherlands

Valerie Shrimplin, United Kingdom

Anna Sidorenko-Dulom, UNESCO

Nelma Silva, Portugal

Mike Simmons, USA

George Smoot, USA

Edgar Soulié, France

Marcelode Oliveira Souza, Brazil

Ivan Šprajc, Slovenia

Grazyna Stasińska, France

Magda Stavinschi, Romania

Indra Subedi, Nepal

Neupane Sudeep, Nepal

Xiaochun Sun, China

Denis Svechkarev, Ukraine

Babak A. Tafreshi, Iran

Naohiro Takanashi, Japan

Petrusevska Tanja, Italy

Olivier Thizy, France

Ivan Thomas, France

William Thuillot, France

Marion Tironneau, France

Enrique Torres, Venezuela

Silvia Torres-Peimbert, Mexico

Sotira Trifourki, United Kingdom

Gérard Trottet, France

Alexandru Tudorica, Romania

Johnson Urama, Nigeria

Evelyn Urama, Nigeria

David Valls-Gabaud, France

Karel A. van der Hucht. IAU

Wim van Driel, France

Sylvie Vauclair, France

Gérard Vauclair, France

Iryna Vavilova, Ukraine

José Antonio Vázquez-Mata, Mexico

Enrique Vázquez-Semadeni, Mexico

Michel Verdenet, France

Christian Vernou. France

Joan Vidal A lcañiz, Spain

Laurent Vigroux, France

Barbara Villone, Italy

Richard Wainscoat, USA

Saskia Walentowitz, Switzerland

Meng Wang, China

Junichi Watanabe, Japan

Elizabeth Wehner, The Netherlands

Michael West, Chile

Patricia Whitelock, South Africa

David Wilgenbus, France

Stephen Wilkins, United Kingdom

Alice Williamson, United Kingdom

Alice Williamson, United Kingdo

Anna Wolter, Italy

Kentaro Yaji, Japan

Yi Yang, China

Yaroslav Yatskiv, Ukraine

Kristine Yun, The Netherlands

Vera Zagainova, Kazakhstan

Philippe Zarka, France

Jesús Zendejas, Mexico

Jin Zhu, China

Shay Zucker, Israel helene_reyss@hotmail.com sribas@am.ub.es var@astro.livjm.ac.uk pennypacker@lbl.goy surenthecreatror@yahoo.com trc@iac.es kaiserv12@yahoo.es grc@mat.ucm.es $\operatorname{lr} \mathrm{i}$ iac.es

archeorely@yahoo.fr rug@le.ac.uk nzelman@laeff.inta.es prusso@eso.org perso.sacco@orange.fr atacama05@wanadoo.fr sarojiny.saddul@gmail.com arsaint-martin@orange rsalazar@astroscu.unam.mx salgado@adlerplanetarium.org gsaliba@columbia.edu fatima@if.ufrgs.br presidente@uai.it

yusuke@costep.hucc.hokudai.ac.jp sauvageotph@wanadoo.fr renaud.savalle@obspm.fr jean.schneider@obspm.fr mschneps@cfa.harvard.edu laurent.schram@louislegrand.fr nseghouani@yahoo.com rishishah@enet.com.np moonkostar@yahoo.co.uk vshrimplin@dsl.pipex.com a.sidorenko@unesco.org nelma@astro.up.p msimm@ucla.ed GFSmoot@lbl.gov edgar.soulie@tele2.fr marcelo@marcelosouza.pro.br sprajc@zrc-sazu.si grazyna.stasinska@obspm.fr magda_stavinschi@yahoo.fr indrasubedi@gmail.com sudeepneupane@gmail.com xcsun@ihns.ac.cn denis@ukrastro.org btafreshi@twanight.org naohiro.takanashi@nao.ac.jp petrusevska@oats.inaf.it olivier.thizy@shelyak.com ivan.thomas@obs-nancay.fr

thuillot@imcce.fr
Marion.Tironneau@ac-paris.fr etorres@cida.ve

silvia@astroscu.unam.mx sotira.t@gmail.com

gerard.trottet@obspm.fr

alex.tudorica@gmail.com

johnson@hartrao.ac.za evelynurama@gmail.com david.valls-gabaud@obspm.fr

K.A.van.der.Hucht@sron.nl wim.vandriel@obspm.fr sylvie.vauclair@ast.obs-mip.fr gerardv@ast.obs-mip.fr vavilova@nas.gov.ua

jvazquez@astroscu.unam.mx e.vazquez@crya.unam.mx michelverdenet@aol.com cvernou@ville-dijon.fr

joanvidal@joanvidal.com vigroux@iap.fr villone@ph.unito.it rjw@ifa.hawaii.ed walentowitz@anthro.unibe.ch wang_m2004@163.com

jun.watanabe@nao.ac.jp e.m.wehner@uu.n mwest@eso.org paw@saao.ac.za

david.wilgenbus@inrp.fr smw@ast.cam.ac.uk lacie@cantab.net

wolfschmidt@math.uni-hamburg.de anna@brera.mi.astro.it yaji@rikkyo.ne.jp ngc4594@tom.com yatskiv@nas.gov.ua kyun@jive.nl

zagainova.vera@gmail.com philippe.zarka@obspm.fr jesusz@astroscu.unam.mx jinzhu@bjp.org.cn

shayz@post.tau.ac.il 